CLINICAL STUDY

\title{
ATLANTIC DIP: simplifying the follow-up of women with previous gestational diabetes
}

\author{
E Noctor, C Crowe, L A Carmody, G M Avalos, B Kirwan, J J Infanti, A O’Dea, P Gillespie, J Newell, B McGuire, \\ C O’Neill, P M O'Shea ${ }^{1}$ and F P Dunne for the ATLANTIC DIP investigators \\ Galway Diabetes Research Centre, National University of Ireland, Galway, Ireland and ${ }^{1}$ Department of Clinical Biochemistry, \\ University Hospital Galway, Galway, Ireland \\ (Correspondence should be addressed to E Noctor; Email: enoctor@yahoo.com)
}

\begin{abstract}
Objective: Previous gestational diabetes (GDM) is associated with a significant lifetime risk of type 2 diabetes. In this study, we assessed the performance of HbAlc and fasting plasma glucose (FPG) measurements against that of $75 \mathrm{~g}$ oral glucose tolerance testing (OGTT) for the follow-up screening of women with previous GDM.

Methods: Two hundred and sixty-six women with previous GDM underwent the follow-up testing (mean of 2.6 years (s.D. 1.0) post-index pregnancy) using HbAlc (100\%), and $75 \mathrm{~g}$ OGTT (89\%) or FPG (11\%). American Diabetes Association (ADA) criteria for abnormal glucose tolerance were used. Design, cohort study, and results: The ADA HbAlc high-risk cut-off of $39 \mathrm{mmol} / \mathrm{mol}$ yielded sensitivity of $45 \%(95 \%$ CI 32,59$)$, specificity of $84 \%(95 \%$ CI 78,88$)$, negative predictive value (NPV) of $87 \%$ $(95 \%$ CI 82,91$)$ and positive predictive value (PPV) of 39\% $(95 \%$ CI 27,52$)$ for detecting abnormal glucose tolerance. ADA high-risk criterion for FPG of $5.6 \mathrm{mmol} / \mathrm{l}$ showed sensitivity of $80 \%$ (95\% CI 66 , $89)$, specificity of $100 \%(95 \%$ CI 98,100$)$, NPV of $96 \%(95 \%$ CI 92,98$)$ and PPV of $100 \%$ (95\% CI 91 , 100). Combining HbAlc $\geq 39 \mathrm{mmol} / \mathrm{mol}$ with FPG $\geq 5.6 \mathrm{mmol} / \mathrm{l}$ yielded sensitivity of $90 \%$ (95\% CI 78 , 96), specificity of $84 \%$ (95\% CI 78, 88), NPV of $97 \%$ (95\% CI 94, 99) and PPV of $56 \%(95 \%$ CI 45, 66). Conclusions: Combining test cut-offs of $5.6 \mathrm{mmol} / \mathrm{l}$ and $\mathrm{HbAlc} 39 \mathrm{mmol} / \mathrm{mol}$ identifies $90 \%$ of women with abnormal glucose tolerance post-GDM (mean 2.6 years (s.D.1.0) post-index pregnancy). Applying this follow-up strategy will reduce the number of OGTT tests required by $70 \%$, will be more convenient for women and their practitioners, and is likely to lead to increased uptake of long-term retesting by these women whose risk for type 2 diabetes is substantially increased.
\end{abstract}

European Journal of Endocrinology $169681-687$

\section{Introduction}

Gestational diabetes mellitus (GDM) is associated with a significant lifetime risk of progression to type 2 diabetes. A recent meta-analysis carried out on the studies conducted over the last 40 years has shown a relative risk of 7.7 for the future development of type 2 diabetes in women with a history of GDM vs women with normal glucose tolerance (NGT) in pregnancy (1). Regular, effective follow-up is therefore essential. The benefits of this are twofold: firstly, retesting allows early detection of those women who have progressed to diabetes, or who have blood glucose concentrations in the pre-diabetic range. This enables the timely commencement of appropriate treatment to prevent diabetes-related complications, or ideally, intervention to prevent progression to overt diabetes. The potential for both intensive lifestyle intervention and metformin treatment to delay or prevent the onset of type 2 diabetes in these women has been previously demonstrated by the Diabetes Prevention Program study (2).
Both interventions were shown to help prevent or delay the onset of type 2 diabetes in women with previous GDM (risk reduction of $53 \%$ for intensive lifestyle intervention and $50 \%$ for metformin treatment). Secondly, regular effective follow-up reduces the risk of undiagnosed type 2 diabetes predating a subsequent pregnancy, and the increased risk to mother and foetus associated with such an event (3).

Despite this, post-partum retesting is haphazard and uptake remains low $(4,5,6,7,8,9,10,11)$, with fasting plasma glucose (FPG) assay or oral glucose tolerance test (OGTT) performed in only 33-58\% of women with previous GDM. Guidelines on how best to follow women with GDM in the post-partum period and beyond vary significantly. The American Diabetes Association (ADA) (12), American Congress of Obstetricians and Gynaecologists (ACOG) (13) and the Fifth International Workshop Conference on Gestational Diabetes (14) all recommend post-partum follow-up with a $75 \mathrm{~g}$ OGTT at 6-12 weeks, while the British National Institute for Clinical Excellence (NICE) 
guidelines (15) recommend follow-up with FPG measurement alone at 6-12 weeks post-partum. Beyond the immediate post-partum period, even more variation is evident. NICE guidelines recommend yearly FPG measurement, while ADA guidelines recommend a follow-up with either FPG, HbA1c, or OGTT on a 1-3 yearly basis after the initial post-partum OGTT. ACOG guidelines recommend a follow-up with either OGTT or FPG test at 3-yearly intervals. The $75 \mathrm{~g}$ OGTT is the current 'gold standard' for the diagnosis of abnormal glucose tolerance, and is the only method by which impaired glucose tolerance (IGT), which is associated with progression to type 2 diabetes (16), and, independently, increased risk of cardiovascular disease $(17,18)$ can be diagnosed. However, for the patient, a minimum 2-h time commitment is required, whereas for the healthcare provider, there are increased costs incurred due to the use of a glucose load, additional phlebotomy services, clinic time and laboratory analyses. An FPG measurement alone, however, misses up to $60 \%$ of women with abnormal 2 -h glucose values (19). A previous study carried out by our research group has shown that the prevalence of GDM by the International Association of Diabetes in Pregnancy Study Groups (IADPSG) criteria during a period of universal screening was $12.4 \%$ (20). The total number of births for the region in which this study was carried out is $\sim 10000$ per annum (21), meaning over 1200 women each year in this region alone would meet IADPSG criteria for GDM. Although not all of these will be new diagnoses, a yearly OGTT for each woman with a history of GDM, as is our current policy, clearly represents a significant clinical and economic burden. Given that retesting using the $75 \mathrm{~g}$ OGTT in clinical practice has been shown to be suboptimal $(4,5,6,7,8$, $9,10,11)$, we set out to design a pragmatic and costeffective recall and retesting program using FPG and $\mathrm{HbA1c}$ assays, or a combination of both, to detect the progression to abnormal glucose tolerance in women with previous GDM.

\section{Subjects and methods}

We recruited women across four centres in the ATLANTIC DIP collaboration who had undergone a $75 \mathrm{~g}$ OGTT during pregnancy in the preceding 5 years (2006-2010), and who had values diagnostic of GDM, using the IADPSG criteria. This 5-year period included an 18-month period of universal screening for women attending for antenatal care. Otherwise, risk factorbased screening was employed. World Health Organization criteria for diagnosis of GDM were used before 2010. These women were identified using our clinical database (DIAMOND, Hicom, Woking) and were invited to attend their closest study centre for retesting. All women were sent a letter, with a follow-up telephone call to arrange an appointment. Of 468 women invited for testing, 342 accepted and 270 (78\%) attended. Of these, four did not have valid $\mathrm{HbAlc}$ measurements, leaving a cohort of 266 women entered into this study. All participants gave informed consent for participation in this prospective cohort study, and institutional research ethics committee approval was obtained before the commencement of the study. Women who met IADPSG criteria only $(n=92 ; 35 \%)$, but not WHO criteria, which were in use at the time of the index pregnancy, were informed that a change in diagnostic criteria and clinical practice had occurred since the index pregnancy. All women had clinical and laboratory parameters during their index pregnancy entered into our clinical database. Of these 266 women, 41 women (15\%) were known to have abnormal glucose tolerance on $75 \mathrm{~g}$ OGTT at their first post-partum visit, 156 women $(59 \%)$ were known to have NGT on a 12 -week post-partum $75 \mathrm{~g}$ OGTT, while 69 (26\%) had not undergone OGTT in the early post-partum period. A $75 \mathrm{~g}$ OGTT was performed in $89 \%(n=237)$, while FPG assay alone was performed on the remaining $11 \%$ $(n=29)$. All women provided a sample for the determination of their $\mathrm{HbA1c}$ levels and participated in a structured standardised interview. Participants underwent an overnight fast, after which blood was drawn into a fluoride oxalate tube for FPG assay and into an EDTA tube for HbA1c assay. A $75 \mathrm{~g}$ glucose load was given (Polycal) and a 2-h post-load plasma glucose was determined. All assays were carried out in the same laboratory (University Hospital Galway) by the persons unaware of the participant's clinical history. Plasma glucose was measured using the hexokinase assay on the Roche Modular $\langle\mathrm{P}\rangle$ Analytics system. The between run analytical coefficient of variation $\left(\mathrm{CV}_{\mathrm{a}} \%\right)$ at a mean plasma glucose of $2.97 \mathrm{mmol} / \mathrm{l}(53.5 \mathrm{mg} / \mathrm{dl})$ and $18.88 \mathrm{mmol} / \mathrm{l}(340.2 \mathrm{mg} / \mathrm{dl})$ was 1.9 and $1.5 \%$ respectively.

HbA1c was measured by reverse phase cation exchange chromatography using the Menarini HA8160 automated haemoglobin analyser. The method was calibrated according to International Federation of Clinical Chemistry (IFCC) standardisation (22). Diabetes Control and Complications Trial (DCCT) units $(\%)$ were derived from the IFCC $(\mathrm{mmol} / \mathrm{mol})$ measurement using the IFCC-DCCT/NGSP (National Glycohaemoglobin Standardisation Program) master equation. The between run $\mathrm{CV}_{\mathrm{a}} \%$ at a mean $\mathrm{HbA1c}$ of $41.6 \mathrm{mmol} / \mathrm{mol}$ (derived DCCT 6\%) and $100.5 \mathrm{mmol} / \mathrm{mol}$ (derived DCCT $11.4 \%$ ) was 2.0 and $1.3 \%$ respectively. ADA criteria were employed for the diagnosis of impaired fasting glucose (IFG), IGT and diabetes mellitus.

Statistical analysis was carried out using PASW Statistics (formerly known as SPSS) version 18 (IBM, New York, NY, USA) and Minitab 15 (Minitab, Inc., State College, PA, USA). Diagnostic accuracy was calculated using sensitivity, specificity, positive predictive value (PPV) and negative predictive value (NPV). 
Receiver-operator characteristic (ROC) curves were constructed for FPG and HbAlc, using the OGTT as the 'gold standard' for the diagnosis of abnormal glucose tolerance, and the area under the curve (AuROC) was calculated.

Differences between mean values of normally distributed continuous variables were compared using Student's $t$-test. Differences between the medians of non-parametrically distributed variables were compared using the Mann-Whitney $U$ test (Fig. 1).

\section{Results}

Of 266 women attending for retesting, $89 \%(n=237)$ had a $75 \mathrm{~g}$ OGTT, while the remaining 11\% $(n=29: 19$ of whom were known to have abnormal glucose tolerance at their first post-partum visit) had FPG test only. Baseline characteristics are shown in Table 1. Of the 266 women tested, $15.4 \%(n=41)$ were known to have abnormal glucose tolerance at their first post-partum visit $(6.8 \%$ IFG, $2.6 \%$ IGT, $4.5 \%$ combined IFG/IGT, 1.5\% diabetes mellitus). At retesting, $81.6 \%$ $(n=217)$ had NGT, while $18.4 \% \quad(n=49 ; 95 \%$ CI 14.2-23.5) had abnormal glucose tolerance (IFG, $n=30 ; 11.3 \%$; IGT, $n=8 ; 3 \%$, combined IFG/IGT, $n=5,1.9 \%$; diabetes mellitus, $n=6,2.3 \%$ ). Of those women meeting the IADPSG criteria, but not the WHO criteria $(n=95), 12 \%(n=11)$ had abnormal glucose tolerance. Baseline characteristics and results at rescreening are summarised in Table 1.

\section{HbA1c}

Table 2 shows the test accuracy of $\mathrm{HbA1c}$ at defined thresholds for predicting abnormal glucose tolerance by ADA criteria. Using the recommended ADA, HbA1c cut-

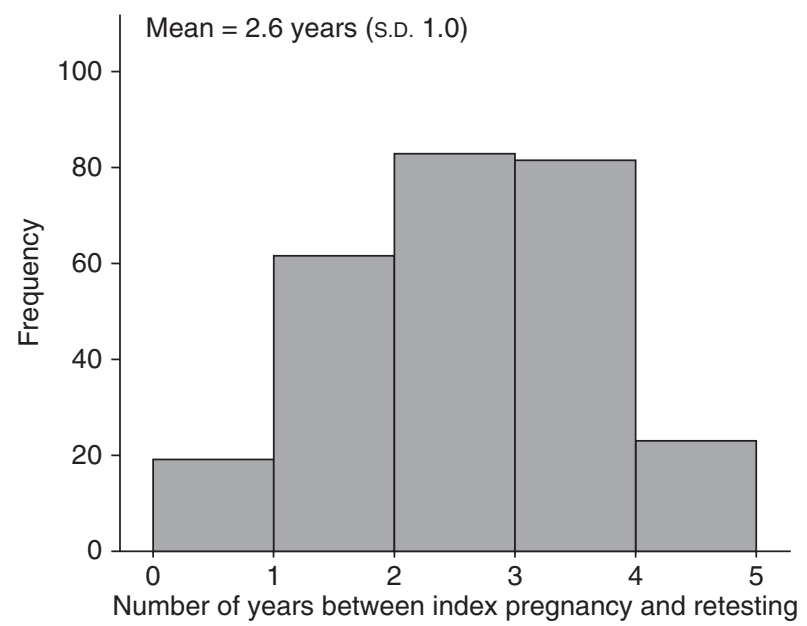

Figure 1 Histogram demonstrating the interval between the delivery date of the index pregnancy and retesting for the current study for all participants $(n=266)$. off for high-risk individuals of $39 \mathrm{mmol} / \mathrm{mol}(5.7 \%)$ yielded a sensitivity of $45 \%$ (95\% CI 32-59), specificity of $84 \%$ (95\% CI 78-88), NPV of $87 \%$ (95\% CI 82-91) and PPV of $39 \%$ (95\% CI 27-52). ROC curve analysis for $\mathrm{HbA1c}$ to predict any abnormal glucose tolerance gave an AuROC of 0.742 (95\% CI 0.663-0.821). AuROC for 2 -h glucose $\geq 7.8 \mathrm{mmol} / \mathrm{l}$ was $0.714(95 \%$ CI 0.591-0.836).

\section{Fasting plasma glucose}

Using the ADA high-risk criterion for FPG $\geq 5.6 \mathrm{mmol} / \mathrm{l}$ to identify any degree of abnormal glucose tolerance, sensitivity was $80 \%$ (95\% CI 66-89), specificity was $100 \%$ (95\% CI 98-100), NPV was 96\% (95\% CI 92-98) and PPV was $100 \%$ (95\% CI 91-100). The characteristics for different cut-offs of FPG when used to screen for abnormal glucose tolerance are summarised in Table 3. ROC curve analysis examining the ability of FPG test alone to predict IGT (i.e. a 2-h plasma glucose of $\geq 7.8 \mathrm{mmol} / \mathrm{l}$ showed an AuROC of 0.609 (95\% CI $0.438-0.779)$ ).

\section{HbA1c and FPG tests combined}

The above results show suboptimal performance using HbA 1c or FPG alone to detect abnormal glucose tolerance in this cohort. We therefore used defined cut-offs of a combination of HbA1c and FPG values to identify higher risk women who should proceed to confirmatory glucose testing with a $75 \mathrm{~g}$ OGTT. Women were classified as meeting the criteria if they met either the specified $\mathrm{HbA} 1 \mathrm{c}$ or the FPG value. We calculated the NPV, PPV, sensitivity and specificity for each defined cut-off of a combination of HbAlc and FPG values. Results are shown in Table 4.

\section{Discussion}

The objective of this study was to evaluate the potential of a new follow-up testing regimen using a combination of FPG and HbAlc measurements to predict the progression to abnormal glucose tolerance post-partum, following initial post-partum assessment with a $75 \mathrm{~g}$ OGTT. Our data suggest that, by combining the decision threshold for HbA1c $\geq 39 \mathrm{mmol} / \mathrm{mol}(5.7 \%)$ and/or an FPG of $\geq 5.6 \mathrm{mmol} / \mathrm{l}, 90 \%(95 \%$ CI $78-96)$ of patients with any degree of glucose abnormality on a $75 \mathrm{~g}$ OGTT are identified, with a specificity of $84 \%$ (95\% CI 78-88). Employing this new approach (requiring only a single blood draw) to identify those higher risk women who should proceed to a $75 \mathrm{~g}$ OGTT would reduce the number of OGTTs performed by almost 70\%. At an estimated cost of Euro 35200 per 1000 women tested (23) using $75 \mathrm{~g}$ OGTT, this new screening regime would reduce the cost of OGTT screening to Euro 10560 ; however, this would of course offset the cost of measuring HbA1c and FPG in each patient. 
Table 1 Baseline characteristics and summary of results. Values are mean (s.D.) unless stated otherwise

\begin{tabular}{|c|c|c|c|c|c|}
\hline Characteristic & $\begin{array}{c}\text { Total GDM } \\
\text { cohort } n=266\end{array}$ & $\begin{array}{c}\text { NGT cohort } \\
n=217\end{array}$ & $\begin{array}{c}\text { Abnormal glucose } \\
\text { tolerance cohort } \\
\qquad n=49\end{array}$ & $\begin{array}{l}P \text { value for } \\
\text { difference }\end{array}$ & $\begin{array}{l}95 \% \mathrm{Cl} \text { for } \\
\text { difference }\end{array}$ \\
\hline Age (years) & $36.6(5)$ & $36.6(5)$ & $36.9(5.1)$ & 0.700 & -1.3 to 1.9 \\
\hline Years since delivery & $2.6(1.0)$ & $2.6(1.1)$ & $2.7(1.0)$ & 0.298 & -0.2 to 0.5 \\
\hline BMl $\left(\mathrm{kg} / \mathrm{m}^{2}\right)$ & $29.7(6.9)$ & $29.1(6.8)$ & $32.4(6.8)$ & 0.002 & 1.2 to 5.5 \\
\hline $\begin{array}{l}\text { Median HbA1c (range) } \\
\quad(\mathrm{mmol} / \mathrm{mol})\end{array}$ & $36(61)$ & $35(19)$ & $38(54)$ & $<0.001$ & 1.5 to 4.5 \\
\hline Fasting glucose $(\mathrm{mmol} / \mathrm{l})$ & $5.1(1)$ & $4.8(0.4)$ & $6.1(1.7)$ & $<0.001$ & 0.9 to 1.9 \\
\hline $2 \mathrm{~h}$ glucose $(\mathrm{mmol} / \mathrm{l})$ & $5.6(1.8)$ & $5.2(1)$ & $8.0(3)$ & $<0.001$ & 1.7 to 3.8 \\
\hline Waist circumference $(\mathrm{cm})$ & $93.3(16.4)$ & $91.8(16.3)$ & $100.1(15.5)$ & 0.001 & 3.2 to 13.4 \\
\hline $\begin{array}{l}\text { Abnormal glucose tolerance } \\
\text { at } 12 \text { weeks }(\%)(n)\end{array}$ & $16 \%(43)$ & NA & NA & NA & NA \\
\hline $\begin{array}{l}\text { Abnormal glucose tolerance } \\
\text { at rescreening }(\%)(n)\end{array}$ & $19 \%(49)$ & NA & NA & NA & NA \\
\hline
\end{tabular}

In our cohort, employing this new screening approach $(\mathrm{HbAlc} \geq 39 \mathrm{mmol} / \mathrm{mol}$ or $\mathrm{FPG}$ of $\geq 5.6 \mathrm{mmol} / \mathrm{l})$ identified a total of 79 women who met the criteria, 44 of whom $(56 \%)$ demonstrate abnormal glucose tolerance using either the OGTT or FPG test. In addition, we now identify a further subgroup of women $(44 \%$, $n=35$ ) who have NGT on OGTT, but meet our criteria by virtue of their $\mathrm{HbA1c}$ value alone. As the HbA1c cut-off of $39 \mathrm{mmol} / \mathrm{mol}$ is the ADA criterion value at which measures to delay or prevent progression to type 2 diabetes should be instituted (12), we would suggest that a $75 \mathrm{~g}$ OGTT adds little to the clinical course of these women.

Therefore, those women with a history of GDM, meeting either the $\mathrm{HbAlc}$ cut-off of $39 \mathrm{mmol} / \mathrm{mol}$ or FPG of $5.6 \mathrm{mmol} / \mathrm{l}$, should undergo at least 3-yearly, and ideally annual $(12,13,14,15)$, follow-up for the assessment of progression to diabetes with $\mathrm{HbAlc}$ and
FPG. At a minimum, individualised dietary and exercise advice should be offered to these high-risk women. However, given the proven efficacy of a structured lifestyle intervention program (2), this should be offered where possible, and a randomised controlled trial is underway at our centre to examine the clinical impact and cost-effectiveness of such a programme in women with previous GDM (24). Of course, if further pregnancy is desired, closer clinical follow-up is needed.

The results of this study, interestingly, are similar to those in recent papers by Megia et al. (25) and Picon et al. (26), who employed similar approaches to predict abnormal post-partum glucose tolerance, albeit describing a lower cut-off: $\mathrm{HbA} 1 \mathrm{c}$ of $37 \mathrm{mmol} / \mathrm{mol}(5.5 \%$, Megia et al.). There are several important differences between the studies, however. Our study shows a sensitivity of 90 vs $82 \%$ (Megia) and $83 \%$ (Picon), while we demonstrate a higher NPV (97\%) vs Picon

Table 2 HbA1c performance using different cut-offs to identify abnormal glucose tolerance (ADA criteria).

\begin{tabular}{lccccc}
\hline $\begin{array}{l}\text { HbA1c } \\
(\mathrm{mmol} / \mathrm{mol})\end{array}$ & $\begin{array}{c}\text { No. of women } \\
\text { meeting criteria } \\
n(\%)\end{array}$ & $\begin{array}{c}\text { Sensitivity } \\
\%(95 \% \mathrm{Cl})\end{array}$ & $\begin{array}{c}\text { Specificity } \\
\%(95 \% \mathrm{Cl})\end{array}$ & $\begin{array}{c}\text { PPV } \\
\%(95 \% \mathrm{Cl})\end{array}$ & $\begin{array}{c}\text { NPV } \\
\%(95 \% \mathrm{Cl})\end{array}$ \\
\hline 32 & $247(93)$ & $98(89,100)$ & $8(5,13)$ & $19(15,25)$ & $95(75,99)$ \\
33 & $232(87)$ & $96(86,99)$ & $15(11,20)$ & $20(16,26)$ & $94(81,98)$ \\
34 & $205(77)$ & $94(83,98)$ & $27(21,33)$ & $22(17,29)$ & $95(86,98)$ \\
35 & $176(66)$ & $86(73,93)$ & $38(32,45)$ & $24(18,31)$ & $92(85,96)$ \\
36 & $140(53)$ & $80(66,89)$ & $53(47,60)$ & $28(21,36)$ & $92(86,96)$ \\
37 & $108(41)$ & $71(58,82)$ & $66(60,72)$ & $32(24,42)$ & $91(85,95)$ \\
38 & $79(30)$ & $55(41,68)$ & $76(70,81)$ & $34(25,45)$ & $88(83,92)$ \\
39 & $57(21)$ & $45(32,59)$ & $84(78,88)$ & $39(27,52)$ & $87(82,91)$ \\
40 & $36(14)$ & $37(25,51)$ & $92(87,95)$ & $50(34,66)$ & $86(81,90)$ \\
41 & $26(10)$ & $31(20,45)$ & $95(91,97)$ & $58(39,74)$ & $86(81,90)$ \\
42 & $17(6)$ & $27(16,40)$ & $98(95,99)$ & $76(53,90)$ & $85(80,89)$ \\
43 & $12(5)$ & $22(13,36)$ & $100(97,100)$ & $92(65,99)$ & $85(80,89)$ \\
44 & $9(3)$ & $18(10,31)$ & $100(98,100)$ & $100(70,100)$ & $84(79,88)$ \\
45 & $8(3)$ & $16(9,29)$ & $100(98,100)$ & $100(68,100)$ & $84(79,88)$ \\
46 & $7(3)$ & $11(5,23)$ & $100(98,100)$ & $100(65,100)$ & $84(79,88)$ \\
47 & $6(2)$ & $12(6,24)$ & $100(98,100)$ & $100(61,100)$ & $83(78,87)$ \\
48 & $6(2)$ & $12(6,24)$ & $100(98,100)$ & $100(61,100)$ & $83(78,87)$
\end{tabular}

${ }^{a}$ Number of participants who meet or exceed $\mathrm{HbA1c}$ cut-off value in adjacent column. 
Table 3 FPG performance using different cut-offs to identify abnormal glucose tolerance (ADA criteria).

\begin{tabular}{lccccc}
\hline $\begin{array}{l}\text { FPG } \\
(\mathrm{mmol} / \mathrm{l})\end{array}$ & $\begin{array}{c}\text { No. of women } \\
\text { meeting criteria }^{\mathrm{a}} \\
n(\%)\end{array}$ & $\begin{array}{c}\text { Sensitivity } \\
\%(95 \% \mathrm{Cl})\end{array}$ & $\begin{array}{c}\text { Specificity } \\
\%(95 \% \mathrm{Cl})\end{array}$ & $\begin{array}{c}\text { PPV } \\
\%(95 \% \mathrm{Cl})\end{array}$ & $\begin{array}{c}\text { NPV } \\
\%(95 \% \mathrm{Cl})\end{array}$ \\
\hline 5 & $126(53)$ & $84(71,91)$ & $61(54,67)$ & $33(25,42)$ & $94(89,97)$ \\
5.1 & $110(41)$ & $82(69,90)$ & $68(61,74)$ & $37(29,46)$ & $94(89,97)$ \\
5.2 & $93(35)$ & $82(69,90)$ & $76(69,81)$ & $44(34,54)$ & $95(90,97)$ \\
5.3 & $70(26)$ & $82(69,90)$ & $86(81,90)$ & $58(46,69)$ & $95(92,98)$ \\
5.4 & $61(23)$ & $80(66,89)$ & $90(85,93)$ & $65(52,76)$ & $95(91,97)$ \\
5.5 & $49(18)$ & $80(66,89)$ & $95(92,97)$ & $81(68,90)$ & $95(92,97)$ \\
5.6 & $39(15)$ & $80(66,89)$ & $100(98,100)$ & $100(91,100)$ & $96(92,98)$ \\
5.7 & $36(14)$ & $73(60,84)$ & $100(98,100)$ & $100(90,100)$ & $94(91,97)$ \\
5.8 & $32(12)$ & $65(51,77)$ & $100(98,100)$ & $100(89,100)$ & $93(89,95)$ \\
5.9 & $28(11)$ & $57(43,70)$ & $100(98,100)$ & $100(88,100)$ & $91(87,94)$ \\
6 & $26(10)$ & $53(39,66)$ & $100(98,100)$ & $100(87,100)$ & $90(86,94)$ \\
6.1 & $25(9)$ & $51(37,64)$ & $100(98,100)$ & $100(87,100)$ & $90(86,93)$ \\
\hline
\end{tabular}

aNumber of participants who meet or exceed FPG cut-off value in adjacent column.

et al.'s (85\%) study. This is a key difference when designing a pragmatic retesting programme for women with previous GDM. For these purposes, a higher sensitivity and NPV are desirable, and in this cohort, do not result in an unacceptable increase in confirmatory testing; the proportion of women meeting $\mathrm{HbA1c/FPG} \mathrm{criteria,} \mathrm{and} \mathrm{therefore} \mathrm{requiring} \mathrm{confirma-}$ tory testing, is $31 \%$ as compared with $29 \%$ in Megia et al.'s study and $47 \%$ in Picon et al.'s study. Both Megia et al.'s and Picon et al.'s studies involve higher risk cohorts, using the National Diabetes Data Group criteria for GDM as opposed to the newer, more stringent, IADPSG criteria, and accordingly, demonstrate a higher prevalence of abnormal glucose tolerance using OGTT; $45.9 \%$ in Picon et al.'s study and $27.8 \%$ in Megia et al.'s study. This is despite a shorter interval to post-partum retesting -3 months (Megia) and 1 year (Picon) vs 2.6 years in our cohort. Other important differences include the ethnic composition of the cohorts - our cohort is $100 \%$ white European, compared with $8.5 \%$ of Megia et al.'s cohort comprising ethnic minorities (predominantly Arabic and Hispanic). Differences in $\mathrm{HbA1c}$ between ethnic groups have been well described previously (27), and our findings may therefore be only applicable to Caucasian women. Given the relatively low GDM prevalence of $12.4 \%$ in previous studies from our group (compared with the $17.8 \%$ across all HAPO centres (28)), the overall burden of follow-up testing, although significant, may be less than that in other centres. Also, the HbA1c assay used in the Megia and Picon studies is DCCT aligned, while our assay is fully metrologically traceable to the newer IFCC standard.

Another study by Kim et al. (29) in 54 women with a history of GDM further demonstrates the limitations of using $\mathrm{HbA1c}$ in isolation to predict abnormal glucose tolerance, showing an AuROC of 0.76 for abnormal glucose tolerance on OGTT, a sensitivity of $65 \%$ and specificity of $68 \%$ for predicting abnormal glucose tolerance when an HbAlc cut-off of greater than or equal to $5.7 \%(39 \mathrm{mmol} / \mathrm{mol})$ is used.

One of the limitations in our study is that $11 \%$ of women $(n=29)$ did not undergo a repeat OGTT for this

Table 4 Combined HbA1c/FPG cut-offs to identify abnormal glucose tolerance (ADA criteria).

\begin{tabular}{lcccccc}
\hline $\begin{array}{l}\text { FPG } \\
(\mathrm{mmol} / \mathrm{l})\end{array}$ & $\begin{array}{c}\text { HbA1c } \\
(\mathrm{mmol} / \mathrm{mol})\end{array}$ & $\begin{array}{c}\text { No. of women } \\
\text { meeting criteria } \\
n(\%)\end{array}$ & $\begin{array}{c}\text { Sensitivity } \\
\%(95 \% \mathrm{Cl})\end{array}$ & $\begin{array}{c}\text { Specificity } \\
\%(95 \% \mathrm{Cl})\end{array}$ & $\begin{array}{c}\text { PPV } \\
\%(95 \% \mathrm{Cl})\end{array}$ & $\begin{array}{c}\text { NPV } \\
\%(95 \% \mathrm{Cl})\end{array}$ \\
\hline 5.3 & 37 & $128(48)$ & $92(81-97)$ & $61(55-68)$ & $35(27-44)$ & $97(93-99)$ \\
5.6 & 37 & $117(44)$ & $90(78-96)$ & $66(59-72)$ & $38(29-47)$ & $97(92-99)$ \\
6.1 & 37 & $112(42)$ & $80(66-86)$ & $66(60-72)$ & $35(27-44)$ & $94(88-96)$ \\
5.3 & 39 & $96(36)$ & $92(81-97)$ & $76(70-81)$ & $47(37-57)$ & $98(94-99)$ \\
5.6 & 39 & $79(30)$ & $90(78-96)$ & $84(78-88)$ & $56(45-66)$ & $97(94-99)$ \\
6.1 & 39 & $68(26)$ & $67(53-79)$ & $84(78-88)$ & $49(37-60)$ & $92(87-95)$ \\
5.3 & 42 & $73(27)$ & $86(73-93)$ & $85(80-89)$ & $58(46-68)$ & $96(93-98)$ \\
5.6 & 42 & $45(17)$ & $84(71-91)$ & $98(95-99)$ & $91(79-97)$ & $96(93-98)$ \\
6.1 & 42 & $32(12)$ & $57(43-70)$ & $98(95-99)$ & $88(72-95)$ & $91(87-94)$ \\
5.3 & 48 & $70(27)$ & $84(71-91)$ & $86(81-90)$ & $59(47-69)$ & $96(92-98)$ \\
5.6 & 48 & $40(15)$ & $82(69-90)$ & $100(98-100)$ & $100(91-100)$ & $96(93-98)$ \\
6.1 & 48 & $26(10)$ & $53(39-66)$ & $100(98-100)$ & $100(87-100)$ & $90(86-94)$
\end{tabular}

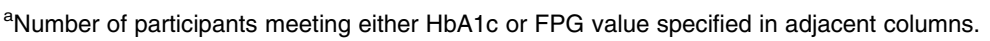


study, but had fasting glucose levels only. On excluding these women from the analysis and taking the proposed cut-offs of $\mathrm{HbAlc}$ of $39 \mathrm{mmol} / \mathrm{mol}(5.7 \%)$ and fasting glucose of $5.6 \mathrm{mmol} / \mathrm{l}$, the sensitivity dropped slightly to $85 \%(95 \%$ CI 70, 94), with a slightly increased specificity of $86 \%(95 \%$ CI 80,90$)$. PPV and NPV are similar at 50\% $(95 \%$ CI 38, 62) and 97\% (95\% CI 94, 99) respectively. However, given that those women who had fasting glucose levels only represent a higher risk group (69\% of these 29 women were known to have abnormal glucose tolerance at their first post-partum visit), we feel that the best approach is to include these women in the analysis. This approach would also be similar to that taken in the clinical management of these women. Also, the majority of the women invited for retesting for this study (89\%) underwent an OGTT. Offering the option of just a single blood draw for FPG and HbA1c assays (or even a single non-fasting sample for $\mathrm{HbA1c}$ alone) may well have a significant effect on the relatively low (58\%) uptake of our offer of retesting. Although this study demonstrates that our approach is clinically feasible, a randomised controlled trial to compare uptake and effectiveness of the various testing modalities would be useful.

In summary, the combination of HbAlc and FPG measurements to predict abnormal glucose tolerance shows results superior to either one used alone. Ninety percent of women with abnormal glucose tolerance are identified using cut-offs of greater than or equal to $39 \mathrm{mmol} / \mathrm{mol}$ for $\mathrm{HbA} 1 \mathrm{c}$ or $5.6 \mathrm{mmol} / \mathrm{l}$ for $\mathrm{FPG}$, while reducing the number of OGTTs performed by over twothirds. This proposed approach is likely to have a significant economic and social benefit from both a patient and healthcare provider perspective, although detailed economic evaluation will be necessary to provide an accurate cost-benefit analysis.

\section{Declaration of interest}

The authors declare that there is no conflict of interest that could be perceived as prejudicing the impartiality of the research reported.

\section{Funding}

The ATLANTIC DIP study was funded by the Health Research Board (HRB) of Ireland. E Noctor reports receiving salary support from Novo Nordisk Ltd.

\section{Author contribution statement}

E Noctor was involved in the study design, collected and analysed data and wrote the manuscript. C Crowe was involved in the study design, collected and analysed data and reviewed the manuscript. L A Carmody was involved in study design, collected data and reviewed the manuscript. G M Avalos was involved in study design, analysed data and reviewed the manuscript. B Kirwan collected data and reviewed the manuscript. J J Infanti was involved in study design, researched data and reviewed the manuscript. A O'Dea was involved in study design, researched data and reviewed the manuscript. J Newell, B McGuire and C O'Neill were involved in study design. P M O'Shea was involved in the study design, analysed data and reviewed the manuscript. F P Dunne is ATLANTIC DIP PI and was involved in study design, analysed data, edited the manuscript and made the decision to publish.

\section{Acknowledgements}

ATLANTIC DIP Collaborators: Dr M Durkan, Portiuncula Hospital Galway, Dr M S Mohammed, Mayo General Hospital, Dr N Ravikumar, Ms T Gallacher, Letterkenny General Hospital, Dr G Gaffney, Ms B Wickham, University Hospital, Galway.

\section{References}

1 Bellamy L, Casas JP, Hingorani AD \& Williams D. Type 2 diabetes mellitus after gestational diabetes: a systematic review and metaanalysis. Lancet 2009373 1773-1779. (doi:10.1016/S01406736(09)60731-5)

2 Ratner RE, Christophi CA, Metzger BE, Dabelea D, Bennett PH, Pi-Sunyer X, Fowler S \& Kahn SE. Prevention of diabetes in women with a history of gestational diabetes: effects of metformin and lifestyle interventions. Journal of Clinical Endocrinology and Metabolism 200893 4774-4779. (doi:10.1210/jc.2008-0772)

3 Balsells M, Garcia-Patterson A, Gich I \& Corcoy R. Maternal and fetal outcome in women with type 2 versus type 1 diabetes mellitus: a systematic review and metaanalysis. Journal of Clinical Endocrinology and Metabolism 200994 4284-4291. (doi:10. 1210/jc.2009-1231)

4 Smirnakis KV, Chasan-Taber L, Wolf M, Markenson G, Ecker JL \& Thadhani R. Postpartum diabetes screening in women with a history of gestational diabetes. Obstetrics and Gynecology 2005106 1297-1303. (doi:10.1097/01.AOG.0000189081.46925.90)

5 Kim C, Tabaei BP, Burke R, McEwen LN, Lash RW, Johnson SL, Schwartz KL, Bernstein SJ \& Herman WH. Missed opportunities for type 2 diabetes mellitus screening among women with a history of gestational diabetes mellitus. American Journal of Public Health 200696 1643-1648. (doi:10.2105/AJPH.2005.065722)

6 Russell MA, Phipps MG, Olson CL, Welch HG \& Carpenter MW. Rates of postpartum glucose testing after gestational diabetes mellitus. Obstetrics and Gynecology 2006 $\mathbf{1 0 8}$ 1456-1462. (doi:10.1097/01.AOG.0000245446.85868.73)

7 Almario CV, Ecker T, Moroz LA, Bucovetsky L, Berghella V \& Baxter JK. Obstetricians seldom provide postpartum diabetes screening for women with gestational diabetes. American Journal of Obstetrics and Gynecology $2008 \quad 198$ 528.e521-528.e525. (doi:10.1016/j.ajog.2007.11.001)

8 Dietz PM, Vesco KK, Callaghan WM, Bachman DJ, Bruce FC, Berg CJ, England LJ \& Hornbrook MC. Postpartum screening for diabetes after a gestational diabetes mellitus-affected pregnancy. Obstetrics and Gynecology 2008112 868-874. (doi:10.1097/ AOG.0b013e318184db63)

9 Hunt KJ \& Conway DL. Who returns for postpartum glucose screening following gestational diabetes mellitus? American Journal of Obstetrics and Gynecology 2008198 404.e401404.e406. (doi:10.1016/j.ajog.2007.09.015)

10 Ferrara A, Peng T \& Kim C. Trends in postpartum diabetes screening and subsequent diabetes and impaired fasting glucose among women with histories of gestational diabetes mellitus: a report from the Translating Research Into Action for Diabetes (TRIAD) Study. Diabetes Care 200932 269-274. (doi:10.2337/ dc08-1184)

11 Shah BR, Lipscombe LL, Feig DS \& Lowe JM. Missed opportunities for type 2 diabetes testing following gestational diabetes: a population-based cohort study. BJOG: an International Journal of Obstetrics and Gynaecology 2011118 1484-1490. (doi:10.1111/ j.1471-0528.2011.03083.x)

12 American Diabetes Association. Standards of medical care in diabetes. Diabetes Care 201235 S11-S63. (doi:10.2337/dc12s011) 
13 ACOG Committee. Opinion no. 435: postpartum screening for abnormal glucose tolerance in women who had gestational diabetes mellitus. Obstetrics and Gynecology 2009113 1419-1421. (doi:10. 1097/AOG.0b013e3181ac06b6)

14 Metzger BE, Buchanan TA, Coustan DR, de Leiva A, Dunger DB, Hadden DR, Hod M, Kitzmiller JL, Kjos SL, Oats JN et al. Summary and recommendations of the Fifth International WorkshopConference on Gestational Diabetes Mellitus. Diabetes Care 2007 30 (Suppl 2) S251-S260. (doi:10.2337/dc07-s225)

15 National Collaborating Centre for Women's and Children's Health (for National Institute for Clinical Excellence). Clinical Guideline 63: Management of diabetes and its complications from preconception to the postnatal period, 2008. London: National Institute for Health and Care Excellence.

16 Sartor G, Schersten B, Carlstrom S, Melander A, Norden A \& Persson G. Ten-year follow-up of subjects with impaired glucose tolerance: prevention of diabetes by tolbutamide and diet regulation. Diabetes $1980 \mathbf{2 9}$ 41-49. (doi:10.2337/diabetes. 29.1.41)

17 Fuller JH, Shipley MJ, Rose G, Jarrett RJ \& Keen H. Coronaryheart-disease risk and impaired glucose tolerance. The Whitehall study. Lancet 19801 1373-1376. (doi:10.1016/S0140-6736(80) 92651-3)

18 Barr EL, Zimmet PZ, Welborn TA, Jolley D, Magliano DJ, Dunstan DW, Cameron AJ, Dwyer T, Taylor HR, Tonkin AM et al. Risk of cardiovascular and all-cause mortality in individuals with diabetes mellitus, impaired fasting glucose, and impaired glucose tolerance: the Australian Diabetes, Obesity, and Lifestyle Study (AusDiab). Circulation 2007116 151-157. (doi:10.1161/ CIRCULATIONAHA.106.685628)

19 Kousta E, Lawrence NJ, Penny A, Millauer BA, Robinson S, Dornhorst A, de Swiet M, Steer PJ, Grenfell A, Mather HM et al. Implications of new diagnostic criteria for abnormal glucose homeostasis in women with previous gestational diabetes. Diabetes Care 199922 933-937. (doi:10.2337/diacare.22.6.933)

20 O'Sullivan EP, Avalos G, O'Reilly M, Dennedy MC, Gaffney G \& Dunne F. Atlantic Diabetes in Pregnancy (DIP): the prevalence and outcomes of gestational diabetes mellitus using new diagnostic criteria. Diabetologia $2011 \quad 54 \quad 1670-1675 . \quad$ (doi:10.1007/ s00125-011-2150-4)

21 Vital Statistics Fourth Quarter and Yearly Summary. Dublin, Ireland: Central Statistics Office, 2012. Dublin, Ireland: The Stationery Office; 2012.58 p. Report No.: 592.

22 Sacks DB, Arnold M, Bakris GL, Bruns DE, Horvath AR, Kirkman MS, Lernmark A, Metzger BE \& Nathan DM. Guidelines and recommendations for laboratory analysis in the diagnosis and management of diabetes mellitus. Diabetes Care 201134 e61-e99. (doi:10.2337/dc11-9998)

23 Gillespie P, O’Neill C, Avalos G, O'Reilly M \& Dunne F. The cost of universal screening for gestational diabetes mellitus in Ireland. Diabetic Medicine 2011 28 912-918. (doi:10.1111/j.1464-5491. 2011.03293.x)

24 Infanti JJ, Dunne FP, O Dea A, Gillespie P, Gibson I, Glynn LG, Noctor E, Newell J \& McGuire BE. An evaluation of Croi MyAction community lifestyle modification programme compared to standard care to reduce progression to diabetes/pre-diabetes in women with prior gestational diabetes mellitus (GDM): study protocol for a randomised controlled trial. Trials $2013 \mathbf{1 4} 121$. (doi:10.1186/1745-6215-14-121)

25 Megia A, Naf S, Herranz L, Serrat N, Yanez RE, Simon I \& Vendrell J. The usefulness of HbA1c in postpartum reclassification of gestational diabetes. BJOG: an International Journal of Obstetrics and Gynaecology 2012119 891-894. (doi:10.1111/j.1471-0528. 2012.03325.x)

26 Picon MJ, Murri M, Munoz A, Fernandez-Garcia JC, GomezHuelgas R \& Tinahones FJ. Hemoglobin A1c versus oral glucose tolerance test in postpartum diabetes screening. Diabetes Care 2012 35 1648-1653. (doi:10.2337/dc11-2111)

27 Herman WH, Ma Y, Uwaifo G, Haffner S, Kahn SE, Horton ES, Lachin JM, Montez MG, Brenneman T \& Barrett-Connor E. Differences in $\mathrm{A} 1 \mathrm{C}$ by race and ethnicity among patients with impaired glucose tolerance in the Diabetes Prevention Program. Diabetes Care 200730 2453-2457. (doi:10.2337/dc06-2003)

28 Sacks DA, Hadden DR, Maresh M, Deerochanawong C, Dyer AR, Metzger BE, Lowe LP, Coustan DR, Hod M, Oats JJ et al. Frequency of gestational diabetes mellitus at collaborating centers based on IADPSG consensus panel-recommended criteria: the Hyperglycemia and Adverse Pregnancy Outcome (HAPO) Study. Diabetes Care 201235 526-528. (doi:10.2337/dc11-1641)

29 Kim C, Herman WH, Cheung NW, Gunderson EP \& Richardson C. Comparison of hemoglobin A1c with fasting plasma glucose and 2-h postchallenge glucose for risk stratification among women with recent gestational diabetes mellitus. Diabetes Care 201134 1949-1951. (doi:10.2337/dc11-0269)

Received 13 June 2013

Revised version received 11 August 2013

Accepted 14 August 2013 